\title{
PEMBERDAYAAN PEREMPUAN NELAYAN MELALUI PELATIHAN DIVERSIFIKASI PRODUK OLAHAN IKAN DI DESA PANGANDARAN KABUPATEN PANGANDARAN
}

\author{
Sri Hartati ${ }^{1}$, Kartib Bayu ${ }^{2}$, Eri Mustari ${ }^{3}$, Ipit Zulfan ${ }^{4}$, Yani Nurhayanti ${ }^{5}$ dan Edwin Karim ${ }^{6}$ \\ ${ }^{1}$ Sekolah Bisnis dan Management, Institut Teknologi Bandung \\ ${ }^{2}$ Sekolah Arsitektur Perencenaan dan Pewilayahan Perkotaan, Institut Teknologi Bandung \\ ${ }^{3}$ Sekolah Ilmu Teknologi Hayati, Institut Teknologi Bandung \\ ${ }^{4}$ Fakultas Ilmu komunikasi, Universitas Padjajaran \\ ${ }^{5}$ Sekolah Bisnis dan Managemen, Institut Teknologi Bandung \\ ${ }^{6}$ Sekolah Tinggi Ilmu Ekonomi Gema Bangsa \\ Email: sri.hartati@sbm-itb.ac.id
}

\begin{abstract}
ABSTRAK. Pemberdayaan masyarakat merupakan upaya untuk meningkatkan kemampuan dan potensi yang dimiliki oleh masyarakat sehingga mereka menjadi mampu mengaktualisasikan diri, harkat serta martabatnya secara maksimal untuk dapat mengembangkan diri secara mandiri. Kegiatan pelatihan ini ditujukan kepada perempuan nelayan di Desa Pangandaran. Sebagian besar perempuan nelayan ini memiliki aktivitas berjualan setiap hari libur ke Pantai Pangandaran. Tujuan pelatihan ini adalah untuk memberikan motivasi kepada perempuan nelayan dalam memanfaatkan peluang dengan membuat diversifikasi produk berbahan ikan. Tahapan pengabdian dilakukan mulai dari sosialisasi, pelaksanaan pengabdian dan evaluasi serta pendampingan. Hasil pelatihan menunjukkan terjadi peningkatan pemahaman terhdap materi yang disampaikan. Peserta sangat antusias dalam mengikuti kegiatan pemberdayaan yang dilakukan serta peserta menilai bahwa materi praktik yang disampaikan merupakan inovasi baru yang belum pernah diterima sebelumnya. Sebagian peserta telah mempraktikkan sendiri materi diversifikasi produk ikan untuk dikonsumsi oleh keluarga. Peserta lainnya memiliki ide untuk dijadikan peluang usaha sehingga diharapkan dapat membantu pendapatan keluarga.
\end{abstract}

Kata kunci: pemberdayaan; perempuan nelayan; diversifikasi produk.

ABSTRACT. Community empowerment is an effort to increase the abilities and potentials possessed by the community so that they become able to actualize themselves, their dignity to the maximum so that they can develop themselves independently. This service activity is aimed at fisherwomen in Pangandaran Village. Most of these fisherwomen have activities selling every holiday to Pangandaran beach. The purpose of this training is to motivate fisherwomen to take advantage of opportunities by diversifying products made from fish. Community service stages are carried out starting from socialization, implementation of community service and evaluation and assistance. The results of the training showed that there was an increase in understanding of the material presented. Participants were very enthusiastic in participating in the training activities carried out and participants considered that the practical material presented was a new innovation that had never been received before. Some of the participants have practiced the material on the diversification of fish products for family consumption. Other participants had an idea to make a business opportunity so that it is hoped that it can help with family income.

Keywords: empowerment; fisherwomen; product diversification

\section{PENDAHULUAN}

Indonesia sangat terkenal dengan wisata pantai yang indah. Pantai-pantai tersebut dijadikan sebagai objek pariwisata yang dapat mendatangkan wisatawan dari domestik maupun mancanegara. Di balik keindahan pantai tersebut, kita dapat melihat kondisi masyarakat yang ada di sekitar pantai tersebut. Di wilayah pesisir pantainya, kita dapat menemukan banyak masyarakat yang tinggal dengan kondisi dan karakteristik keluarga yang khas. Ketika para suami atau anak remaja pergi melaut maka kehidupan didominasi oleh wanita dan anak-anak. Berdasarkan informasi awal para nelayan melaut antara 1-2 minggu, paling sedikit tiga hari. Ketika akan pergi melaut para nelayan mempersiapkan bekal untuk keperluan selama berlayar. Sebagian besar modal untuk bekal diperoleh dari para pemilik kapal. Sementara keluarga yang ditinggalkan diberikan bekal seadanya, bahkan harus meminjam dulu ke tetangga atau saudara untuk memenuhi kebutuhan sehari-hari. Hal ini dapat mengakibatkan tanggung jawab kehidupan sehari-hari harus dilakukan oleh perempuan. Keadaan ekonomi mereka jauh dari sejahtera, maka dengan berpindahnya tanggung jawab ke tangan perempuan menjadikan meraka harus bekerja keras untuk mencukupi kebutuhan keluarganya (Susilowati, 2006).

Perempuan atau istri nelayan memiliki peran yang ganda ketika suami mereka pergi melaut. Peran yang diemban oleh perempuan istri nelayan dilakukan dalam berbagai hal baik untuk urusan internal keluarga maupun urusan di luar keluarga (publik). Peran perempuan istri nelayan yang sangat terlihat adalah dalam aktivitas ekonomi. Hal terlihat dari alokasi waktu yang mereka curahkan selama ini. Alokasi waktu yang dicurahkan oleh perempuan digunakan untuk mencari penghasilan keluarga dengan berjualan ke wilayah 
pantai yang banyak dikunjungi wisatawan. Aktivitas berjualan akan meningkat pada hari libur nasional atau libur panjang. Hal ini menunjukkan bahwa kondisi ekonomi ketika nelayan tidak melaut maka mereka tidak mendapatkan penghasilan, sementara kebutuhan keluarga terus berjalan. Dalam kondisi seperti ini peran seorang istri sangat diperlukan untuk membantu memenuhi kebutuhan keluarga, dan diperlukan alternatif-alternatifuntuk mengatasi kesulitan ekonomi keluarga dalam memenuhi kebutuhan hidup. Wanita secara umum memiliki multi peran yang menghendaki adanya keselarasan dalam melaksanakan tugasnya (Lubis \& Ovami, 2018). Besarnya peran istri nelayan membuat pentingnya dilakukan pemetaan kedudukan dan peran perempuan pesisir dalam rangka mendukung upaya-upaya pembangunan optimalisasi peran perempuan dalam meningkatkan kesejahteraan sosial masyarakat di wilayah pesisir, khususnya pada masyarakat nelayan (Kusnadi, 2003).

Beberapa program telah diluncurkan oleh Kementerian Kelautan dan Perikanan, namun belum semua masyarakat nelayan menerima program tersebut. Kondisi kehidupan sebagai nelayan dengan tangkapan hasil laut yang sangat fluktuatif semakin menambah ketidakpastian seiring penghasilan. Keluarga nelayan yang sepenuhnya bergantung terhadap laut pasti sangat merasakan dampak dari kondisi tersebut. Apalagi jika musim paceklik tiba akan menambah sulit kehidupan keluarga nelayan dan solusi yang banyak digunakan oleh kelaurga nelayan adalah harus berutang untuk memenuhi kebutuhan. Berlatar belakang dari kondisi tersebut maka diperlukan suatu langkah atau upaya memberdayakan mereka. Upaya untuk pemberdayaan perempuan nelayan dalam memanfaatkan waktu dan sumber daya ikan yang ada merupakan kegiatan yang sangat bermanfaat bagi mereka dalam upaya meningkatkan pendapatan dan peingkatan kesejahteraan keluarga. Perempuan nelayan ikut ambil bagian dalam menambah pendapatan keluarga. Selain menjalankan peran reproduksi yang berkaitan dengan pekerjaan rumah tangga, perempuan nelayan juga memiliki peran sosial kemasyarakatan dengan aktif dalam gerakan sosial dalam upaya mempertahankan ruang hidup dan ruang kelolanya (Firdaus \& Rahadian, 2015; Haryanto, 2008; Nurlaili \& Koeshendrajana, 2010; Nurlaili \& Muhartono, 2017; Wahyuni, 2017). Salah satu upaya peningkatan pendapatan keluarga nelayan ini dilakukan melalui pelatihan diversifikasi produk olahan berbahan baku ikan.

Pangandaran merupakan sebuah wisata pantai yang terletak di bagian tenggara provinsi Jawa Barat dan berbatasan langsung dengan Kabupaten Cilacap, Jawa Tengah. Berdasarkan data dari Dinas Kelautan, Perikanan, dan Ketahanan Pangan Kabupaten Pangandaran (BPS Kabupaten Ciamis, 2018), potensi perikanan laut Kabupaten Pangandaran terdapat di 7 lokasi TempatPelelangan Ikan(TPI) yaitu TPIMadasari, TPI Legok Jawa dan TPI Muaragatah di Kecamatan Cimerak, kemudian TPI Batu Karas dan TPI Nusawiru di Kecamatan Cijulang, TPI Parigi di Kecamatan Parigi dan TPI Minasari di Kecamatan Pangandaran.

Wisatawan yang datang ke Pantai Pangandaran berasal dari berbagai daerah di Jawa Barat maupun dari provinsi lainnya di Indonesia dan termasuk wisatawan dari luar negeri. Tujuan wisatawan yang datang untuk menikmati pantai. Selain ramai dikunjungi oleh wisatawan yang ingin berlibur sambil menikmati keindahan alamnya termasuk juga wilayah cagar alam, ternyata Pangandaran juga dijadikan tempat yang harus dikunjungi oleh pecinta kuliner terutama makanan berbahan ikan laut segar. Olahan makanan laut (sea food) yang lezat dan segar pun menjadi daya tarik yang menjanjikan dari pantai ini. Tentunya hal tersebut merupakan sebuah potensi yang luar biasa untuk dikembangkan.

Potensi membuat makanan dari ikan menjadi makanan yang berbeda akan mendatangkan daya tarik tersendiri dari wisatawan. Salah satu makana plahan yang terbuat dari ikan segara adalah makan beku (frozen food). Makanan beku (frozen food) menjadi terkenal dan banyak dikonsumsi oleh masyarakat terutama ketika wabah COVID19 mulai melanda Indonesia termasuk Pangandaran. Permintaaan masyarakat terhadap produk makanan beku karena diberlakukan PSBB (Pembatasan Sosial Berskala Besar) atau social distancing, saat masyarakat tidak leluasa keluar rumah. Diversifikasi produk berbahan baku ikan segar menjadi suatu inovasi yang perlu dikembangkan di daerah Pangandaran dengan mengoptimalkan potensi sumberdaya perempuan nelayan. Sehubungan dengan hal tersebut, diperlukan inovasi yang berbeda agar bisnis kuliner di Pangandaran tetap terus berkembang.

Adapun tujuan dari kegiatan pengabdian ini adalah untuk meningkatkan sumberdaya manusia di bidang kewirausahaan agar kehidupan mereka meningkat, menjadi wirausaha mandiri dari sisi ekonomi dan secara umum dapat mengentaskan kemiskinan masyarakat di wilayah tersebut. Target sasaran kegiatan pengabdian adalah para perempuan nelayan yang ada Desa Pangandaran Kabupaten Pangandaran berjumlah lima belas orang. Dampak dari kegiatan pemberdayaan perempuan nelayan melaui diversifikasi produk ikan laut adalah:

1. Bergeraknya perekonomian di Desa Pangandaran khususnya dan Kecamatan Pangandaran Ciamis pada umumnya.

2. Secara parsial kegiatan ini diupayakan untuk mengurangi tingkat pengangguran khususnya untuk kalangan perempuan.

3. Secara mental diharapkan akan muncul rasa 
percaya diri dari perempuan untuk dapat beusaha sendiri dalam meningkatkan pendapatan keluarga.

4. Adanya perempuan nelayan yang terbina sebagai tenaga mandiri.

Sementara output yang diharapkan dari kegiatan pengabdian ini adalah agar perempuan nelayan memiliki pengetahuan secara teknis maupun manajemen mengenai diversifikasi pengolahan ikan laut, pengelolaan usaha serta proses pengemasan hasil produk olahan. Hasil pelatihan diharapkan dapat dilaksanakan sehingga dapat meningkatkan pendapatankeluarga serta dapat membukakesempatan kerja baru untuk masyarakat wilayah Pantai Pangandaran. Diharapkan istri nelayan dapat menjadi wirausaha yang mandiri dan turut mengentaskan kemiskinan masyarakat di wilayah tersebut. Selain itu, keberlangsungan usaha yang menunjang ekonomi keluarga terutama pada masa pandemi Covid19, yang saat ini sangat berdampak pada stabilitas ekonomi yang mereka jalani karena turunnya angka kunjungan wisatawan pada masa Pembatasan Sosial Berskala Besar (PSBB) wilayah Jawa Barat

\section{METODE}

Metode pendekatan yang dilakukan pada kegiatan pemberdayaan ini adalah pembelajaran orang dewasa andragogi dengan menggunakan prinsip partisipatif. Metode ini melibatkan secara aktif pihak-pihak yang relevan (stakeholders) dalam mengkaji tindakan yang sedang berlangsung dalam rangka melakukan perubahan ke arah yang lebih baik. Komposisi pembelajaran pada kegiatan pemberdayaan perempuan nelayan dilakukan melalui teori $(30 \%)$ dan materi ppraktik (70\%).

\section{HASIL DAN PEMBAHASAN}

Kegiatan pemberdayaan perempuan nelayan dilaksanakan ketika pandemi Covid19 masih berlangsung sehingga tetap mematuhi protokol kesehatan. Peserta diwajibkan menggunakan masker mulai masuk ruang pelatihan, mencuci tangan serta menjaga jarak tempak duduk. Kegiatan pengabdian ini diikuti oleh 15 (lima belas) orang perempuan nelayan yang membantu suami mereka (nelayan) dan tidak mempunyai usaha tetap namun mempunyai potensi untuk mengembangkan bisnisnya sesuai dengan potensi yang ada di Desa Pangandaran.

Tahapan pelatihan dilakukan dimulai dengan mengidentifikasi dan melakukan penelusuran jumlah perempuan nelayan di Desa Pangandaran, dan tahap selanjutnya menentukan peserta yang dapat mengikuti pelatihan. Penentuan peserta pelatihan bekerjasama dengan Kelompok Swadaya Masyarakat (KSM) Desa Pangandaran, sebagai salah satu wadah pemberdayaan yang ada di Desa Pangandaran.
Pelatihan ini dilaksanakan di ruangan Balai Desa Pangandaran. Tahapan selanjutnya adalah evaluasi dan pendampingan kepada seluruh peserta pelatihan.

Materi yang disampaikan meliputi:

1. Motivasi yang berkaitan dengan motivasi diri dan orang lain untuk mengikuti pelatihan, keinginan untuk belajar, keiinginan untuk mengubah keadaan ke situasi yang lebih baik. Motivasi tumbuh dan bisa digali dengan mengoptimalkan potensi diri yang dimiliki para peserta pelatihan.

2. Materi dasar-dasar pengelolaan pembukuan, keuangan pribadi dan usaha. Materi ini lebih menekankan pada pengelolaan keuangan pribadi dengan keuangan usaha. Mengenal jenis-jenis biaya dan tujuan pengeloaan keuangan.

3. Materi pemasaran, peluang usaha, media sosial diberikan sebagai upaya penambahan pengetahuan dalam memasarkan produk, media yang digunakan dalam pemasaran seperti media sosial Facebook, WhatsApp, dan instagram.

4. Peserta diperkenalkan pada Asosasi Pemandu Wirausaha Indonesia (APWI), sebuah asosiasi yang konsen membina UKM di Jawa Barat. Selanjutnya usaha peserta pemberdayaan akan dipasarkan melalui website atau portal APWI.

5. Materi praktik membuat fish cake dan fish nugget. Materi praktik pengolahan berbahan ikan laut sebagai upaya menambah variasi produk dari yang sudah ada.

Tabel 1 menunjukkan bahwa sebagian besar peserta telah mengalami perubahan ke arah yang lebih baik atau lebih paham terhadap materi yang diberikan dalam pelatihan. Perubahan yang terjadi terutama pada aspek kognitif, aspek afektif dan aspek psikomotorik.

Pada saat proses pelatihan, respon peserta sangat antusias karena materi praktik yang diberikan belum pernah didapatkan meskipun sudah ada yang memberikan pelatihan. Situasi proses belajar mengajar sangat kondusif. Peserta menyimak dengan baik materi yang disampaikan oleh pelatih. Suasana belajar dibangun dengan diskusi dua arah sehingga materi yang tidak dipahami dapat didiskusikan secara langsung. Keceriaan peserta terlihat semangat karena kegiatan pelatihan yang diselenggarakan merupakan kegiatan pelatihan pertama kali saat pandemi Covid19 merebak di Pangandaran. Produk jadi yang dihasilkan adalah fish cake dan fish katsu merupakan diversifikasi produk yang sangat digemari oleh peserta karena produk ini belum diketahui dan dipraktikan sehingga sangat menginspirasi peserta untuk melakukan usaha dengan membuat dan menjualnya.

Hasil evaluasi kegiatan pengabdian selesai menunjukkan bahwa para peserta belum seluruhnya 
Tabel 1. Hasil Rekapitulasi Tingkat Pemahaman Peserta Terhadap Materi pelatihan

\begin{tabular}{|c|c|c|c|c|c|c|c|c|c|}
\hline \multirow{3}{*}{ No } & \multirow{3}{*}{ Materi } & \multicolumn{8}{|c|}{ Tingkat Pemahaman (\%) } \\
\hline & & \multicolumn{4}{|c|}{ Sebelum Mengikuti Pelatihan } & \multicolumn{4}{|c|}{ Setelah Mengikuti Pelatihan } \\
\hline & & SP & $\mathrm{P}$ & $\mathrm{KP}$ & $\mathrm{TP}$ & SP & $\mathrm{P}$ & KP & $\mathrm{TP}$ \\
\hline 1 & Karakter yang harus dimiliki seorang Wirausaha & 1 & 3 & 8 & 3 & 13 & 2 & 0 & 0 \\
\hline 2 & Cara Memotivasi diri sendiri dan orang lain & 0 & 7 & 6 & 2 & 0 & 13 & 2 & 0 \\
\hline 3 & Model Usaha secara berkelompok & 5 & 5 & 3 & 2 & 7 & 8 & 0 & 0 \\
\hline 4 & Potensi dan Peluang Usaha Pengolahan Ikan & 4 & 4 & 3 & 4 & 8 & 7 & 0 & 0 \\
\hline 5 & Teknik pengolahan fish katsu & 0 & 0 & 1 & 14 & 15 & 0 & 0 & 0 \\
\hline 6 & Teknik pengolahan fish cake & 0 & 0 & 0 & 15 & 15 & 0 & 0 & 0 \\
\hline 7 & Teknik Pemasaran Produk & 2 & 10 & 2 & 1 & 5 & 5 & 5 & 0 \\
\hline 8 & Teknik Penyusunan Perencanaan Usaha & 0 & 4 & 8 & 3 & 8 & 6 & 1 & 0 \\
\hline 9 & Pengelolaan Keuangan Usaha & 5 & 7 & 1 & 2 & 10 & 5 & 0 & 0 \\
\hline 10 & Penjualan melalui social media. & 3 & 5 & 7 & 0 & 10 & 5 & 0 & 0 \\
\hline
\end{tabular}

Keterangan: $\mathrm{SP}=$ Sangat paham, $\mathrm{P}=$ paham, $\mathrm{KP}=$ Kurang paham, $\mathrm{TK}=$ Tidak Paham

mengoptimalkan peluang usaha dari hasil ppraktik disebabkan kondisi di daerah pangandaran dan secara keseluruhan masih merebaknya Covid19. meskipun daerah wisata pantai sudah dibuka namun pengunjung masih sepi sehingga produk yang ada pun tidak laku. Namun demikian tidak menyurutkan motivasi para perempuan nelayan untuk berusaha membuat kreativitas produk berbasis ikan. Salah satu peserta bahkan sudah mencoba untuk menjual produk fish cake ke tetangga serta untuk dikonsumsi sendiri

\section{SIMPULAN}

Berdasarkan kegiatan pemberdayaan yang telah dilakukan pada perempuan nelayan di Pangandaran Jawa Barat dapat disimpulkan bahwa pemberdayaan merupakan salah satu kebutuhan yang diperlukan oleh perempuan nelayan sebagai upaya untuk memaksimalakan kesempatan dan peluang yang dimiliki perempuan nelayan. Tujuan pemberdayaan untuk meningkatkan aspek penegtahuan, motivasi serta keterampilan sehingga mereka dapat berkontribusi dalam penciptaan pendapatan keluarga. Perubahan pemahaman ke arah lebih paham oleh perempuan nelayan setelah mengikuti pelatihan diharapkan akan lebih memotivasi peserta untuk memanfaatkan peluang usaha dengan diversifikasi produk yang telah diberikan pada pelatihan.

Adanya kerjasama dan kolaborasi berbagai institusi dalam melaksanakan pemberdayaan akan lebih optimal dalam upaya menciptakan dan meningkatkan serta memberikan kesempatan bagi perempuan nelayan untuk memberdayakan dirnya dalam menopang kehidupan kelaurga. Institusi yang dapat berkolaborasi adalah instansi terkait, Dinas Kelautan, Dinas Koperasi dan UKM, Dinas Perindustrian dan Perdagangan, insitusi pendidikan, perusahaan, Koperasi Nelayan, Kelompok Swadaya Masyarakat (KSM) serta pihak lainya yang memiliki simpati terhadap kondisi perempuan nelayan di Pangandaran.

\section{UCAPAN TERIMA KASIH}

Ucapan terima kasih kepada LPPM ITB, Marketing Communication SBM, Pemerintah Desa Pangandaran, KSM Pangandaran yang telah mendukung terselenggaranya kegiatan pengabdian masyarakat ini.

\section{DAFTAR PUSTAKA}

BPS Kabupaten Ciamis. (2018). Kabupaten PangandarandalamAngka(2018). Diaksesdari https://pangandarankab.bps.go.id/publication/ 2018/08/16/907e76e6ddf107aafa6a7252/ kabupaten-pangandaran-dalam-angka-2018. htmlFirdaus, M., \& Rahadian, R. (2015). Peran Istri Nelayan dalam Meningkatkan Pendapatan Rumah Tangga (Studi Kasus di Desa Penjajab, Kecamatan Pemangkat, Kabupaten Sambas). Jurnal Sosial Ekonomi Kelautan Dan Perikanan, 10(2), 241-249. https://doi.org/10.15578/jsekp.v10i2.1263

Haryanto, S. (2008). Peran Aktif Wanita Dalam Peningkatan Pendapatan Rumah Tangga Miskin: Studi Kasus Pada Wanita Pemecah Batu Di Pucanganak Kecamatan Tugu Trenggalek*.JurnalEkonomi Pembangunan: Kajian Masalah EkonomiDan Pembangunan, 9(2), 216-227. https://doi.org/10.23917/jep. v9i2.1025

Kusnadi. (2003). Akar Kemiskinan Nelayan. Yogyakarta: LKiS.

Lubis, A. S., \& Ovami, D. C. (2018). Pemberdayaan Istri Nelayan Melalui Pelatihan Olahan Ikan Dalam Rangka Penguatan Ekonomi Kerakyatan Dan Peningkatan Pendapatan Nelayan Di Desa Pekan Sialang Buah Kec. Mengkudu Serdang Bedagai. Amaliah: Jurnal 
Pengabdian Kepada Masyarakat, 2(2), 178183. https://doi.org/10.32696/ajpkm.v2i2.199

Nurlaili, \& Koeshendrajana, S. (2010). Peran Perempuan Bajo dalam Rumah Tangga Perikanan Tangkap di Wuring, Kecamatan Alok Barat, Kabupaten Sikka, Provinsi Nusa Tenggara Timur. Jurnal Sosial Ekonomi Kelautan Dan Perikanan, 5(2), 199-210. https://doi.org/http://dx.doi.org/10.15578/ jsekp.v5i2.5801

Nurlaili, \& Muhartono, R. (2017). Peran Perempuan Nelayan dalam Usaha Perikanan Tangkap Pesisir Teluk Jakarta. Jurnal Sosial Ekonomi Kelauta Dan Perikanan, 12(2),
203-212. Diakses dari http://ejournalbalitbang.kkp.go.id/index.php/sosek/article/ download/6481/5681

Susilowati, S. P. (2006). Peranan Istri Nelayan dalam Meningkatkan Kesejahteraan Rumah Tangga (di Desa Kabongan Lor Kecamatan Rembang Kabupaten Rembang). (Universitas Negeri Semarang). Retrieved from https:/lib.unnes. ac.id/995/1/1932.pdf

Wahyuni, Y. (2017). Peran Produksi, Reproduksi dan Sosial Kemasyarakatan Perempuan Pengolah Kerang Hijau di Muara Angke, Jakarta Utara. Jurnal Perempuan, 22(4), 94-118. 